\title{
Intrauterine device quo vadis? Why intrauterine device use should be revisited particularly in nulliparous women?
}

This article was published in the following Dove Press journal:

Open Access Journal of Contraception

16 January 2015

Number of times this article has been viewed

\section{Dirk Wildemeersch' \\ Norman Goldstuck ${ }^{2}$ \\ Thomas Hasskamp ${ }^{3}$ \\ Sohela Jandi ${ }^{4}$ \\ Ansgar Pett ${ }^{4}$}

'Gynecological Outpatient Clinic and IUD Training Center, Ghent, Belgium; ${ }^{2}$ Department of Obstetrics and Gynaecology, Faculty of Medicine and Health Sciences, Stellenbosch University and Tygerberg Hospital, Western Cape, South Africa;

${ }^{3}$ GynMünster, Münster, ${ }^{4} \mathrm{Gynecological}$ Outpatient Clinic, Berlin, Germany
Correspondence: Dirk Wildemeersch Gynecological Outpatient Clinic and IUD Training Center, F Rooseveltlaan 43-44, 9000 Ghent, Belgium

Email d.wildemeersch@skynet.be
Background: Long-acting reversible contraceptive (LARC) methods, including intrauterine devices (IUDs) and the contraceptive implant, are considered the best methods for preventing unintended pregnancies, rapid repeat pregnancy, and abortion in young women. An opinion paper of 2012 by the American College of Obstetricians and Gynecologists recommends Mirena and Paragard for use in nulliparous and adolescent women. However, these IUDs are not designed for young women and are not optimal as they often lead to early discontinuation.

Objective: This article was written with the objective to respond to the urgent need to improve intrauterine contraception as it is likely that the objectives of LARC will not be met without significant improvement of IUD design. Anatomical variations in size and shape of the uterus are not sufficiently considered, producing harm and suffering, which often lead to early removal of the IUD.

Proposed problem solving: The article describes why IUDs should be revisited to meet the challenge of LARC and proposes how to solve these problems. The opinion statement presented here may be considered provocative but is based on hundreds of women with IUD problems who consult or are referred to the practices of the authors of this article due to the disproportion between the IUD and their small uterine cavity. The solution is simple but requires a revision of the current design of IUDs. One-dimensional (longitudinal) IUDs are likely to be the first option. Framed devices with shortened transverse arm and IUDs which adapt to the width of the given uterus are viewed as second best.

Conclusion: One of the reasons of the high unintended pregnancy rate in the USA may be the paucity of suitable IUDs. Also, the legal climate in the USA seems to be a problem for developers as many lawsuits have recently been reported. Clinical studies conducted in young nulliparous and adolescent women suggest that IUDs that fit well in the uterine cavity, like a shoe, result in better tolerance, less side effects, and last but not least, higher use continuation rates.

Keywords: IUD screening, counseling, frameless IUD/IUS, adapted IUDs, efficacy, tolerance, continuation rate

\section{Introduction}

The primary objective of any contraceptive is to avoid unintended pregnancy. The latest figures published by Trussell and his team show that the pill, the contraceptive patch, and the vaginal ring have a typical 1 -year pregnancy rate of $9 \% .{ }^{1}$ Side effects and noncompliance are the main causes for these high failure rates. For this reason, long-acting reversible contraceptive (LARC) methods (eg, intrauterine devices [IUDs] and implants) are advocated. LARC is vigorously promoted by societies such as the American College of Obstetricians and Gynecologists (ACOG), the US-based 
Association of Reproductive Health Professionals, the World Health Organization (WHO), the European Society of Contraception and Reproductive Health Care, the UK Faculty of Sexual and Reproductive Healthcare, and other organizations, as these methods are thought to be the solution for the global problem of unintended pregnancy. ${ }^{2}$ Among LARCs, the IUD, (the denomination is used to indicate both copper and hormone-releasing intrauterine systems (IUSs), or only to indicate copper IUDs) is by far preferred by young US women. ${ }^{3}$ The most frequently reported reasons for liking the IUD (only one copper IUD is available in the USA) are ease of use and reliability, and for the levonorgestrel intrauterine system (LNG-IUS), lighter menstrual cycles. In Europe, IUDs and the LNGIUS are more popular than implants because of the burden of insertion and surgical removal. ${ }^{4}$ However, if the IUD/ IUS causes pain and erratic or heavy menstrual bleeding, which are unfortunately common side effects, it will most likely be removed and replaced, often by a less effective method or no method at all. It should be realized that, prior to deciding to remove the IUD/IUS, many women have gone through a period of months of cramping pain, trying to endure the method as they have no alternative. This is not the aim of LARC. Positioning LARC for use in nulliparous and adolescent women can only achieve its goal if the method is continued to be used. ${ }^{5}$ Hence, tolerance is the major issue. Side effects and complications may incite women to file complaints as, for instance, lawsuits in the USA against contraceptive manufacturers are commonplace. ${ }^{6}$ The ability to tolerate an IUD/IUS is the result of several factors related to the provider, the receiver, and the IUD/IUS in its own right. It appears that IUDs and IUSs have the highest probability of being accepted by women if attention is given to these factors starting with the provision of correct information to dispel myths and misconceptions, and providing proper selection of the intrauterine method, comfort at insertion, and correct fitting.

The results of IUD/IUS trials in young and adolescent women are conflicting. Some report high tolerance rates, while others the opposite. Most of these trials have been conducted for a short period of time, 6 months to 1 year, rarely with the licensed "LARC effective period" of 5 years because too many women drop off. ${ }^{7-14}$

This article will focus on three main determinants of IUD use: screening and counseling prior to IUD/IUS insertion, IUD/IUS selection, and comfort during insertion. Recommendations are provided to maximize continuation of use, and other ways to reduce unintended pregnancy in young women are discussed.

\section{Screening Screening for infection}

The risk of pelvic infection, which may lead to infertility, ectopic pregnancy, and chronic pelvic pain, remains one of the major concerns of IUD providers as well as of women. It is known that this is a misinterpretation of the data and has unfortunately resulted in many unintended pregnancies by limiting women's access to a long-term contraceptive method. There is good scientific evidence that the risk of pelvic inflammatory disease (PID) is not increased after the first month following insertion of the IUD. Investigations by WHO showed that the risk of PID is limited to the first 20 days after insertion. ${ }^{15}$ The incidence of PID in IUD users remains very low and seems to be associated with young women with the high prevalence of bacterial vaginosis and cervicitis rather than with the insertion of an IUD. The presence of vaginosis increases the infection risk significantly. ${ }^{16}$ Antibiotic treatment has not been shown to be beneficial except in women with an increased risk of bacterial endocarditis (eg, women with a valvular prosthesis). ${ }^{17}$ Bacteremia can occur during insertion and removal of an IUD but is rare. ${ }^{18}$ In general, screening for bacterial vaginosis and the prescription of antibiotics are not required, except if there are signs of cervicitis. Screening could however be recommended in the presence of risky behavior (eg, multiple sexual partners or recent Chlamydia trachomatis or Neisseria gonorrhea infection). Reassessment of PID, possibly attributable to an IUD, however, confirmed that the risk is similar to women who do not have an IUD inserted. ${ }^{19}$ The rate of PID in IUD users is low even in regions where the prevalence of sexually transmitted infections is high. ${ }^{20}$ Clinical evidence has shown that previous use of a copper IUD is not associated with an increased risk of tubal occlusion among nulligravid women. ${ }^{21}$

In conclusion, WHO suggests that the benefits of IUDs generally outweigh the risks in women of any age, whether parous or not, and that IUDs can be inserted in women younger than 20 , provided that these women are at low risk of sexually transmitted infections. However, WHO advises against the use of IUDs in women who have had PID in the previous 3 months. ${ }^{22}$ ACOG recommends to screen all adolescents at the time of or before IUD insertion. ${ }^{5}$ The IUD can be placed on the same day and treatment administered if the test results are positive (a single oral dose of $1 \mathrm{~g}$ of azithromycine or $2 \times 100 \mathrm{mg}$ of oral doxycycline for 7 days).

\section{Screening for uterine anomalies and dimensions of the uterine cavity} Screening for congenital uterine anomalies

Congenital uterine anomalies are deviations resulting from maldevelopment as a consequence of abnormalities 
occurring during embryonic life of the Müllerian ducts. ${ }^{23}$ As no universally agreed standardized classification systems exist, the true population prevalence of congenital uterine anomalies is difficult to assess. Three-dimensional ultrasound is the easiest method to diagnose uterine anomalies. It has the advantage of being noninvasive and also provides quantitative information on parameters such as fundal indentation or septum length, which is not possible to assess with the endoscopic methods or hysterosalpingography.

Chan et al found, overall, 5.5\% uterine anomalies diagnosed in an unselected population. Arcuate uteri are the most common abnormalities in the unselected population affecting $3.9 \%$ of all women. Subseptate or septate uteri have a prevalence of $2.3 \%$. Bicornuate uteri are uncommon $(0.4 \%)$ and $0.1 \%$ of cases present a unicornuate uterus. The prevalence of uterus didelphys is approximately $0.3 \%$ in an unselected population. ${ }^{24}$ Interestingly, a similar prevalence of uterine anomalies was reported in a study by Jurkovic et al on 1,046 women attending a gynecological ultrasound clinic for a variety of indications. ${ }^{25}$ Table 1 summarizes these estimates.

Recently, the European Society of Human Reproduction and Embryology and the European Society of Gynecological Endoscopy proposed a new updated classification system to provide a comprehensive clinical orientation of congenital anomalies of the uterus. Anomalies are classified into the following main classes based on anatomical deviations derived from the same embryological origin (Figure 1): U0 or normal uterus; U1 or dysmorphic uterus; U2 or septate uterus; U3 or bicorporeal uterus; U4 or hemi-uterus (Figure 1). ${ }^{26}$

In conclusion, screening for congenital anomalies is not practical to carry out routinely. It should be realized, however, that malformation of the uterus may be a reason for IUD problems and side effects such as malposition of the IUD, displacement, partial and total expulsion of the IUD, and uterine perforation, and should be considered if any of these occur.

Table I Estimates of the prevalence of congenital uterine anomalies

Prevalence of uterine anomalies in unselected population Arcuate uterus

Subseptate and septate uterus

$2.3 \%$

Bicornuate uterus

Unicornuate uterus

$0.4 \%$

Uterus didelphys

$0.1 \%$

Overall

$0.3 \%$

$5 \%-7 \%$

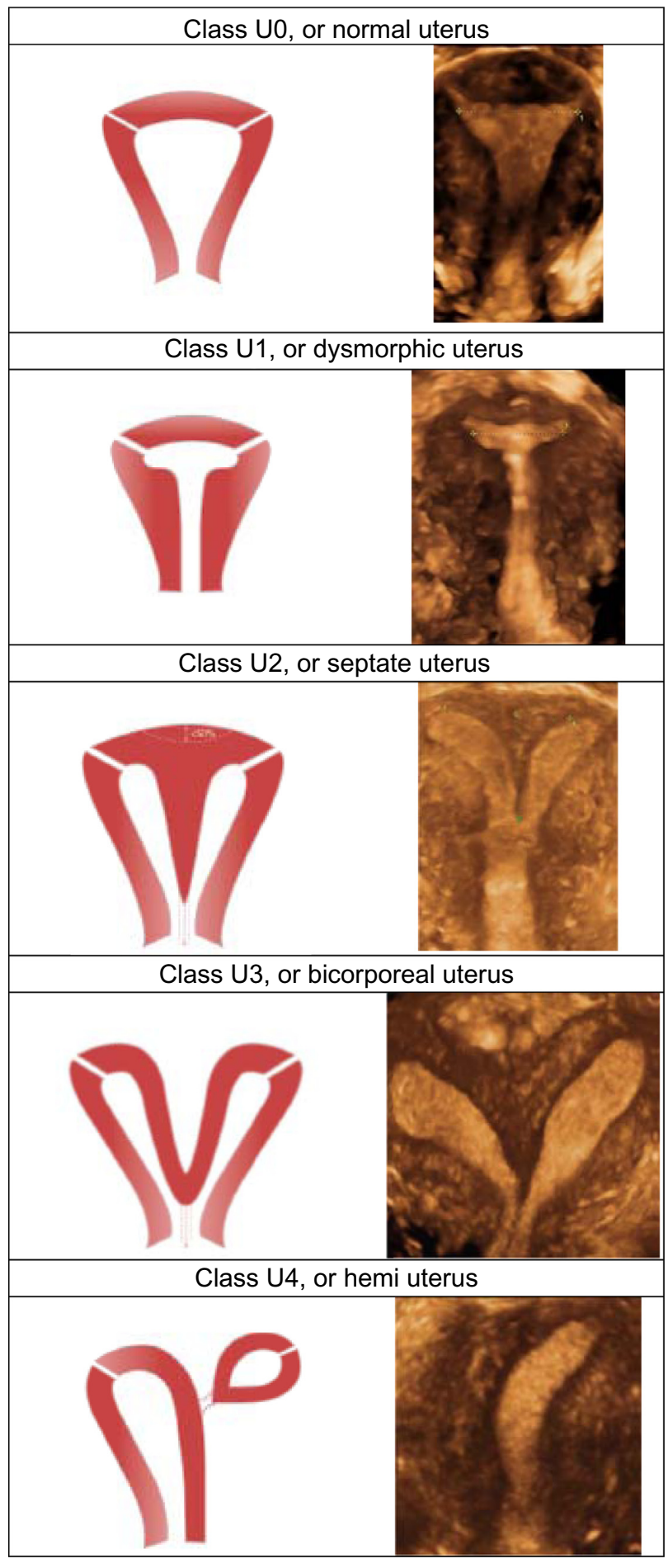

Figure I Classification of main uterine anomalies.

Notes: Schematic representation (left); three-dimensional sonographic images (right). Adapted from Grimbizis GF, Gordts S, Di Spiezio A, et al. The ESHRE/ESGE consensus on the classification of female genital tract congenital anomalies. Human Reproduction. 2013;28:2032-2044. ${ }^{26}$

Abbreviations: ESHRE, European Society of Human Reproduction and Embryology; ESGE, European Society of Gynecological Endoscopy.

\section{Screening for uterine dimensions and IUD selection}

As uterine cavities differ considerably in size in all women, and the uterus changes in size and volume during the menstrual cycle, it is unreasonable to expect one standard-sized IUD to fit 
uterine cavities with different sizes and volumes. Disproportion between the IUD and the uterine cavity often leads to cramping pain, embedment, displacement, partial or total expulsion of the IUD, unintended pregnancy (due to downward displacement, partial or total expulsion), and abnormal or heavy uterine bleeding, resulting in removal of the IUD. ${ }^{27}$

A major contribution to the understanding of IUD-related side effects has been made by Kurz and Hasson, as well as other researchers, some 30 years ago. ${ }^{28,29}$ These researchers were able to confirm, using measuring instruments (cavimeter, wing sound), that uterine cavities in nulliparous and parous women are usually narrow and concluded that IUDs should be adapted to the width of the uterine cavity to avoid pain and embedment and possible secondary perforation. The latter may be due to the imbalance between the size of the IUD and that of the uterine cavity, causing production of asymmetrical forces. The uterine muscle seems capable of generating enough force to cause an IUD to perforate the myometrium provided it is applied asymmetrically. ${ }^{30}$

Attention to the size and shape of the uterus prior to inserting an IUD is of paramount importance. The uterine width, a parameter directly related to IUD tolerance and continuation of use, was assessed recently by ultrasound by two independent research groups in Finland and in the USA. It was found in 165 nulliparous women that the median width of the uterine cavity measured at its upper level was $24.4 \mathrm{~mm}$ (range 13.8-35.0 mm). In 101 women (62.7\%), the transverse width was below this distance. ${ }^{31}$ In line with these findings, Benacerraf et al found a similar cavity width in 91 nulliparous women. They compared women with abnormally and normally located IUDs, with respect to their indication for three-dimensional ultrasound examination, and found that the proportion of patients whose principal indication for scanning was bleeding, pain, or both was significantly greater in those with an abnormally located IUD, including embedded IUD, compared with those whose device showed normal location. The mean width of the uterine cavity of nulliparous women in their study was $27 \mathrm{~mm}$ (range 20.2-34.1 mm) which is narrower than the width of a standard IUD (32 mm). They suggest that physicians should consider ultrasonography to measure the uterine cavity before inserting an IUD. ${ }^{32}$

Most conventional IUDs have a transverse diameter of between $28 \mathrm{~mm}$ and $32 \mathrm{~mm}$. The transverse dimensions of many uteri are far less than the length of the transverse arm of the Paragard IUD (Duramed Pharmaceuticals Inc., Pomona, NY, USA) and Mirena LNG-IUS (Bayer, Berlin, Germany), which is $32 \mathrm{~mm}$, resulting in side effects due to distortion, displacement, and expulsion.
When studying Paragard and Mirena in young nulliparous and adolescent women, Berenson et al and Rasheed and Abdelmonem (as well as other authors) found high rates of discontinuation and commented that the most plausible cause of early discontinuation (up to $40 \%$ after 6 months to 1 year) in this subset of women is the disproportion between the IUD and the uterine cavity. ${ }^{12,13}$ It seems logical, therefore, that the provider should realize that the only way to obtain a high continuation rate is by using an IUD that is not wider than the width of the uterine cavity. The new smaller version of Mirena, named Jaydess (Skyla in the USA), has a transverse arm length of $28 \mathrm{~mm}$. The results of initial clinical trials ${ }^{33}$ are encouraging, but this $28 \mathrm{~mm}$ transverse arm may still be too long for many women. An illustration is given in Figure 2. Frameless copper and frameless LNG-IUSs could be optimal from this point of view. Figure 3 (upper row) shows the uterine cavities of young women, assessed by three-dimensional ultrasound before a decision was made to insert an IUD. Which IUD would suit them best? Figure 3 (lower row) also shows small uteri which were, however, fitted with the frameless IUD. As the frameless IUD/IUS, having virtually only a longitudinal dimension of clinical relevance, it will fit all normal uterine cavities, and is therefore probably the best option for most women. Currently most IUD providers make a one-dimensional assessment (length) by sounding the threedimensional uterine cavity before placing a two-dimensional IUD or IUS. This one-dimensional assessment of the uterus is most likely to provide good results if followed by the use of a one-dimensional (frameless) IUD/IUS. This is simple reasoning based on the geometry of the uterine cavity.

An alternative approach is to shorten the arms of existing IUDs or design IUDs with different lengths of transverse

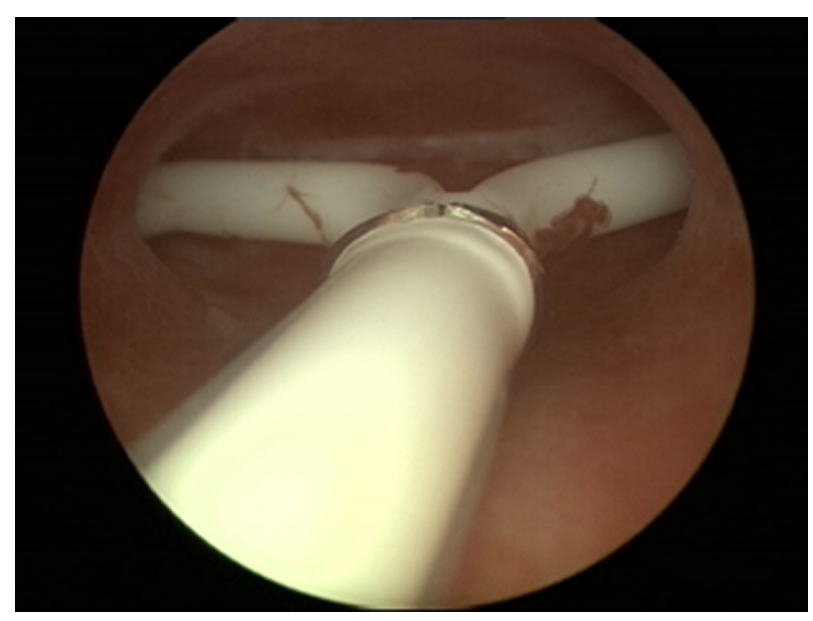

Figure 2 Hysteroscopic picture of Jaydess/Skyla causing pain complaints due to the too long transverse arm in a nulliparous woman. 

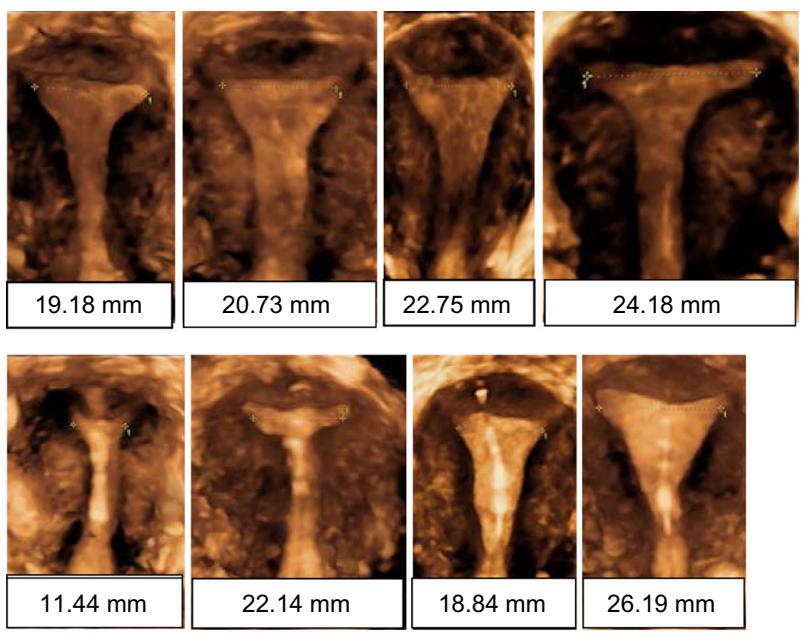

Figure 3 3D ultrasound in nulliparous women

Notes: Screening three-dimensional (3D) ultrasonography performed in women desiring intrauterine contraception with measurement of the fundal transverse width (upper row); uterine cavities of nulliparous women fitted with a frameless copper IUD. The transverse width of the uterine cavity is indicated below each figure (lower row). Abbreviation: IUD, intrauterine device.

arms. Figure 4 shows a T-shaped IUD of which the transverse arm was trimmed to a length of $18 \mathrm{~mm}$. The flexible transverse arms of an experimental $\Omega$-shaped LNG-IUS allow adaptation to the width of the uterine cavity (Figure 5).

In conclusion, studies suggest that high user continuation can be achieved by optimizing the relationship between the IUD and the uterine cavity. ${ }^{34,35}$ An IUD that does not fit well will often lead to side effects (ie, pain, bleeding, embedment, expulsion) and subsequent removal of the IUD. Measuring the width of the uterine cavity may not be practical in most settings. Therefore, frameless IUDs and IUDs with shorter transverse arms should be considered especially for the young.

\section{Counseling - upfront cost, myths, and misconceptions Upfront cost is a major barrier}

Most patients want to know the cost of contraception especially for LARC methods as the upfront costs are an important barrier and a deterrent to the use of IUDs in countries which do not reimburse IUDs. It may therefore be useful to work out payment schemes for lower income women. Unlike traditional methods of contraception such as condom and pill, the IUD/IUS, which has a life span of 5 years, is very reasonably priced in the European Union at between 100 Euros and 350 Euros, including IUD/IUS insertion. However, this is still a barrier for many women, especially for the higher priced IUDs. The average wholesale price in the USA of the LNG-IUS is $\$ 844$, and the copper IUD is

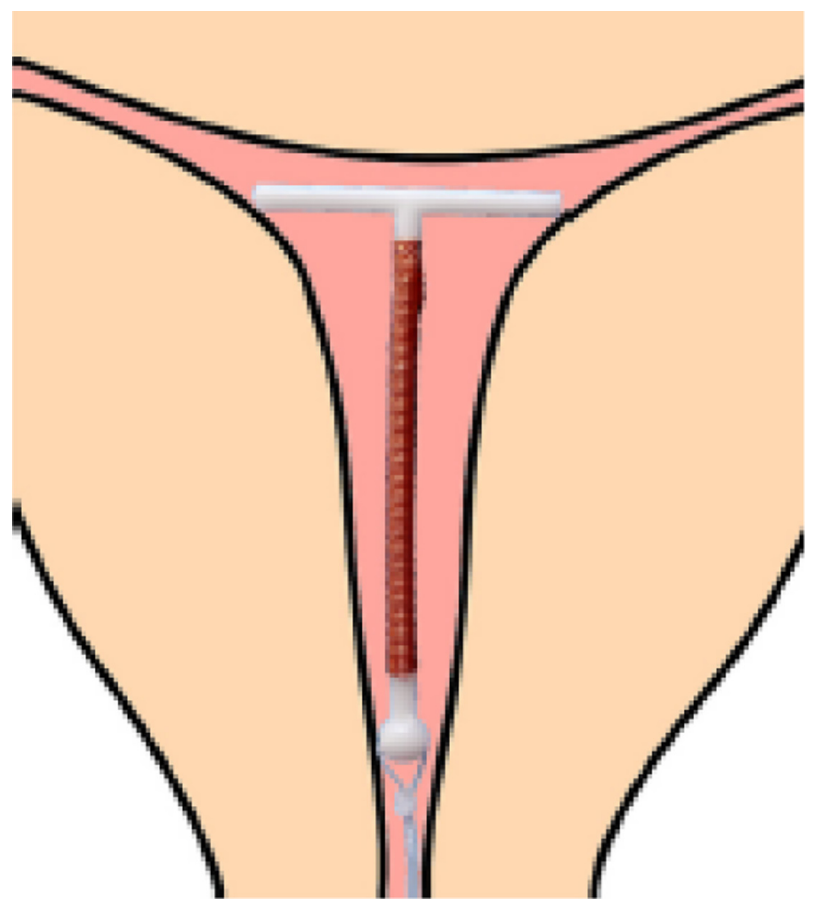

Figure $4 \mathrm{~A}$ narrow uterine cavity fitted by a trimmed T-shaped IUD with transverse arm length of $18 \mathrm{~mm}$.

Abbreviation: IUD, intrauterine device.

$\$ 718$, the costs of the office visit and insertion procedure not included. ${ }^{36}$ In some European countries, this one-off purchase cost can be settled by an inexpensive and easy financing option. Usually, the woman receives the individual credit agreement within a few weeks. In the USA, contraceptives may be reimbursed under the so-called Obamacare provision (Affordable Care Act). Provision of no-cost contraception has been shown to decrease unintended birth rate, abortions, and repeat abortions. ${ }^{37}$ An example of a payment scheme is given

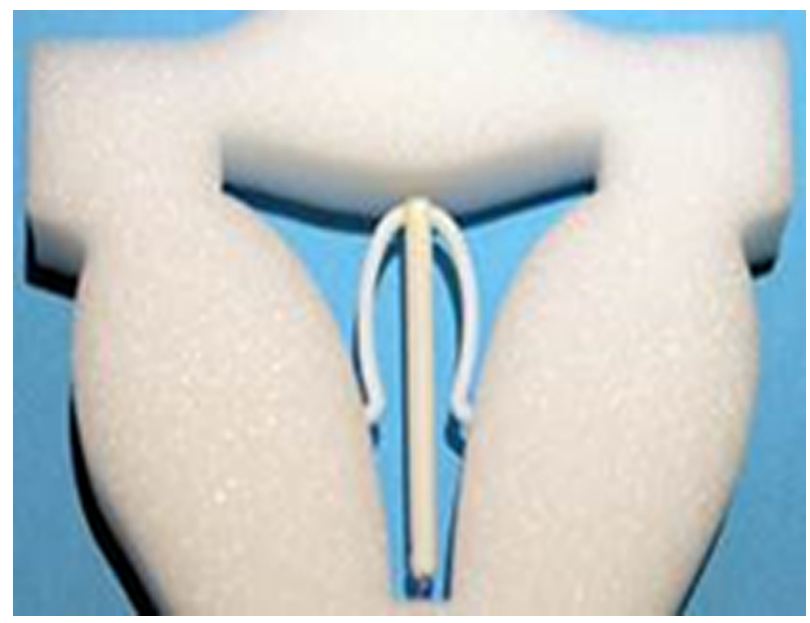

Figure 5 An experimental LNG-IUS capable of adaptation to the individual width of uterine cavity.

Abbreviation: LNG-IUS, levonorgestrel intrauterine system. 
in Table 2. Due to the introduction of financing provision, women no longer have to miss the advantages of an IUD providing secure protection for years on especially favorable terms. If the payoff period is 18 months, about 42 months are for free. Compared to other contraceptive methods, the IUD/IUS is the most economical (Table 3).

\section{Myths and realities about IUD use}

Outdated perceptions among women about IUDs continue to negatively impact their use. IUDs are often not selected as the first option because they are misunderstood. It may still surprise many people that the IUD is safer than other forms of contraception. ${ }^{38}$ Therefore, due attention should be given to keeping women correctly informed about new developments in this field, in comparison to other methods. An emerging body of research has disproved a number of contraindications to intrauterine contraception. Specifically, women of any age or parity and those who are postpartum or post-first-trimester abortion are all eligible for intrauterine contraception. The IUD is also highly suitable for emergency contraception as it will provide continuous protection. The benefits of intrauterine contraception outweigh the risks of a wide variety of medical conditions that might contraindicate the use of combined hormonal oral contraceptives. Providers should be aware of the WHO or the US medical eligibility criteria for contraceptive use. ${ }^{22,39}$ Table 4 discusses the most common myths and misconceptions about IUD use. ${ }^{40-43}$

\section{Attention to comfort during IUD insertion}

As IUDs are becoming more popular, the issue of pain control is often discussed as related to IUD insertion in young women. Practical advice during counseling is important and should include information about discomfort during pelvic examination, the pain associated with IUD insertion, and information about the benefits and risks of IUD use. Insertion pain cannot be predicted. Ultrasonography does not give additional information to predict pain. According to Kaislasuo et al, dysmenorrhea is the only predictor of severe or intolerable insertion pain due to increased uterine/cervical contractility. ${ }^{31}$ Identifying means of sufficient analgesia, especially in

Table 2 Monthly cost for financing IUD/IUS

\begin{tabular}{llll}
\hline Cost of IUD/IUS & \multicolumn{4}{l}{ Financing period (months) } \\
\cline { 2 - 4 } in Euro $(€ 350)$ & $\mathbf{6}$ & $\mathbf{1 2}$ & $\mathbf{1 8}$ \\
\hline Monthly cost & $€ 58.33$ & $€ 29.60$ & $€ 20.5 \mathrm{I}$ \\
\hline
\end{tabular}

Note: Data from Medipay (https://www.medipay.de). ${ }^{79}$

Abbreviations: IUD, intrauterine device; IUS, intrauterine system.
Table 3 Comparison of the cost of various forms of contraception in Germany in 2014

\begin{tabular}{lll}
\hline Method & Total cost & $\begin{array}{l}\text { Cost per } \\
\text { month }\end{array}$ \\
\hline Condom & $0.30-I €$ per unit & \\
Combined oral contraception pill & - & $€ 5-12$ \\
3-monthly injectable & - & $€ 10$ \\
Subcutaneous progestin implant & $€ 350-450$ & $€ 9-13$ \\
Vaginal ring & - & $€ 13-20$ \\
IUD/IUS & $€ 150-350$ & $€ 3-8$ \\
\hline
\end{tabular}

Abbreviations: IUD, intrauterine device; IUS, intrauterine system.

nulliparous women, is important. Equally important is an appropriate patient-friendly setting accommodated with indirect light. Not to be forgotten is the use of a narrow and short speculum in young women to facilitate access to the cervix. A $1.0-1.5 \mathrm{~cm}$ wide speculum is sometimes necessary in young women. A too large speculum often causes more pain than the IUD insertion procedure. Listening to music during the procedure decreases procedural pain. ${ }^{44}$

The injection of a drop of lidocaine or mepivacaine in the anterior lip of the cervix before placement of a (preferably) atraumatic forceps is a good habit, especially if the patient is anxious or if slow closing of the Allis forceps causes pain or prior to placement of a toothed forceps (eg, Pozzi forceps). The use of a dental syringe with extra-fine needle is highly practical and can also be used for local or loco-regional anesthesia.

After disinfection and gentle straightening of the uterus, a "cotton swab test" (soaked in antiseptic solution) can be done to test the tightness of the internal cervical os and to obtain information on pain sensation. If the test provokes severe pain, additional local anesthesia can be provided prior to sounding the uterus. Additional instrumentation (eg, os finder, cervical dilator), except for a sound to measure the length and flexion of the uterus, is rarely necessary if the test shows that that cavity can be entered easily.

Many believe that the use of misoprostol greatly facilitates IUD insertion. ${ }^{45}$ We recommend the use of $200-400 \mu \mathrm{g}$ of misoprostol, orally or vaginally, 3 hours before IUD insertion. Others prefer to place the tablets vaginally in the posterior fornix the night before the procedure (9-12 hours before). Despite conflicting published data about the benefits of misoprostol, significant differences were found in nulliparous women between groups using misoprostol, $400 \mu \mathrm{g}$ vaginally, 4 hours before insertion, compared to placebo with less difficulty and less moderate-to-severe pain at IUD insertion. ${ }^{46}$ It may be that the vaginal route could be preferable as plasma concentrations of misoprostol remain substantially higher than when administered by the oral or sublingual routes. However, 
Table 4 Myths and misconceptions that still exist related to intrauterine contraception

Myths and miscon
IUDs cause abortion
IUDs cause pelvic
inflammatory disease

IUDs cause pelvic
inflammatory disease

IUDs cause ectopic pregnancy

IUDs cannot be used by nulliparous women

IUD insertion is painful

IUDs cause pain and embedment

IUDs are not effective

IUDs are expelled and cause perforation

IUDs cause abnormal and heavy menstrual bleeding

\section{Reality}

IUDs do not terminate a pregnancy. The primary contraceptive effect of intrauterine contraception is the prevention of fertilization and implantation by interfering with sperm motility and survival. The reaction of the intrauterine foreign body with the endometrium activates the release of leukocytes and prostaglandins which act not only in the uterus but also in the oviduct and cervix to impede sperm and egg development The issue of increased risk or greater severity of sexually transmitted infection (STI) among IUD users has been a prominent concern. However, the rate of PID is low, with cases concentrated in the first 20 days after insertion. The reason for the increased risk during the first weeks after insertion is that bacteria in the vagina and cervix can be transported through the cervical canal into the uterine cavity. It is important to tell the IUD user that for the majority of the users, fertility is restored immediately after removal of the device; irrespective of whether the IUD was used for a few months or for many years

The risk of ectopic pregnancy in IUD users has been thoroughly investigated. The risk is ten times lower in IUD/IUS users than in the general population of women using no contraception $(0.0-0.5 / 1,000$ women vs $3.25-5.25 / 1,000$ women). This finding has been confirmed by a meta-analysis of 16 case-control studies. ${ }^{80}$ A previous ectopic pregnancy is not a contraindication for the use of an IUD/IUS Another myth is that women over 25 years or older are the best candidates for IUD use, and that women over 35 are the ideal candidates. This belief, based on the fear of pelvic infection (PID) and the potential for resulting infertility, is no longer justified. There is no biological reason to conclude that a young woman is at higher risk than an older woman provided they have similar sexual behaviors

One of the reasons of the underuse of the IUD is the fear of insertion pain. The insertion of an IUD is not usually a painful procedure. However, many women, nulliparous women in particular, fear insertion and this may be an important reason not to select an IUD. Several measures can be used to reduce patient discomfort during the insertion and removal of the IUD: premedication, local anesthesia, and cervix relaxing agents, and anxious patients should ask for it. Should physicians pay attention to pain relief, it is likely that many more women will request IUDs as their method of contraception. Taking care of pain relief is important. When counseling, the provider should inform the woman about the insertion procedure and about the measures he/she will take to make insertion less uncomfortable ${ }^{81}$

IUDs do not necessarily have to cause pain during use if properly fitted in the uterine cavity. Providers should select a particular IUD/IUS based on an estimation of the size of the uterine cavity. A standard IUD size will not fit cavities of every size and shape. Frameless IUDs are particularly useful for use in nulliparous and adolescent women as they are flexible and do not cause any distention of the uterus. IUDs that are too big will often embed in the uterine wall. Each woman should request her doctor to select an IUD/IUS that fits into her uterus IUDs protect 20 times better than the pill, the contraceptive patch, and the vaginal ring against intrauterine and ectopic pregnancy, in contrast with the general belief. The commonly held opinion is that oral contraceptives are more effective than IUDs. Similarly, physicians and the general public are often poorly informed about the effectiveness of IUDs and the effectiveness of contraceptives in general Total expulsion of a conventional IUD occurs in 5\%-10\% of women during the first year of use, with an increased risk in nulliparous women. The majority of expulsions occur during the first months after insertion, with I\%-2\% per year thereafter. Frameless, anchored IUDs reduce the risk of expulsion approximately five-tenfold, on condition that the IUD is properly inserted. The overall risk of perforation with IUD insertion is around I-2/I,000 women. Perforation is often caused by unskilful insertion, poor technique due to the absence of training, and lack of attention to contraindications. Women should discuss these issues with their providers. IUDs that do not fit can progressively migrate through the uterine wall due to forceful contractions of the uterus

Erratic and heavy menstrual bleeding is the most common cause for IUD discontinuation. The impact on menstrual blood loss with copper IUDs can be minimized by reducing the surface area of the foreign body. The small frameless GyneFix 200 IUD, releasing copper ions from the outer as well as inner surface of the copper tubes, does not increase menstrual blood loss in contrast to all other copper IUDs simply because it is much smaller. On the other hand, all hormone-releasing intrauterine systems strongly reduce menstrual blood loss. Many users of hormonal IUDs develop amenorrhea (have bleed-free periods). In many countries, this is becoming a trend. Several measures are possible to manage erratic menstrual bleeding and spotting if present

Notes: This is a list of the most frequent myths and misconceptions. Data from WHO Scientific Group on the Mechanism of Action Safety and Efficacy of Intrauterine Devices, ${ }^{38}$ Center for Disease Control and Prevention, ${ }^{39}$ Wildemeersch et al ${ }^{40}$ and Ortiz et al. ${ }^{41}$

Abbreviations: IUD, intrauterine device; PID, pelvic inflammatory disease; IUS, intrauterine system.

most women prefer the oral route to vaginal application. ${ }^{47}$ If misoprostol is used for cervical priming, it is recommended that a nonsteroidal analgesic be added to reduce its prostaglandin-mediated side effects and uterine cramping. Of relevance, misoprostol could help reduce failed insertion. In a recent study among nulliparous women, 27 of 138 (19.6\%) TCu380A IUD insertions were unsuccessful for emergency contraception. ${ }^{48}$ Some physicians claim that applying heat 
to the lower abdomen (using electric heating pad, or a microwave-heated cherry seed pillow) may significantly reduce painful sensations. ${ }^{49}$ If the patient is having severe discomfort with the insertion of the sound or requires cervical dilation, then the administration of a paracervical block or even conscious sedation (such as propofol or midazolam) can be used. However, this is rarely necessary and perhaps only in extremely anxious women.

\section{Neglected indications for IUD use}

Intrauterine contraception could play a significant role to reduce unintended pregnancies by inserting IUDs for emergency, postabortal, and postpartum contraception. IUDs are still underused in these situations; a lost opportunity to substantially reduce the occurrence of repeat unintended pregnancies and induced abortions.

\section{Emergency contraception}

In 1976, copper IUDs were shown to be highly effective for emergency contraception. ${ }^{50}$ They have three main advantages over oral hormonal emergency contraception: 1) Efficacy is higher for a copper IUD, with pregnancy rates not exceeding $0.1 \%$, compared with much higher pregnancy rates of progestin-only and ulipristal emergency contraception. ${ }^{51,52}$ 2) A copper IUD can be inserted at least 5-7 days after unprotected intercourse, or up to 5 days after the earliest estimated day of ovulation. In this situation, the copper IUD may act by preventing implantation; when used long-term, it usually prevents fertilization. ${ }^{53}$ 3) Once inserted, an IUD can provide ongoing contraception for 5 years or more. A recent study suggested that women appear to have interest in "same-day" IUD insertion following unprotected intercourse, particularly better educated young women and those who had a prior unwanted pregnancy. ${ }^{54}$

\section{Immediate postabortion contraception}

Women who have an IUD inserted immediately after an abortion have fewer pregnancies and repeat abortions than women who schedule insertion of an IUD during a follow-up visit. ${ }^{55}$ The IUD/IUS is also probably the most appropriate birth control method to reduce the number of repeat abortions. ${ }^{56}$ Gynecologists and obstetricians have an ethical obligation to do everything that is possible to ensure that postabortion contraception, with a focus on LARC methods, becomes an integral part of abortion and postabortion care, in line with the recommendations of the International Federation of Gynecology and Obstetrics and of several other organizations. ${ }^{1}$ Frameless IUDs have been successfully used for the prevention of repeat abortions. Continuation rates after 1 year were over $90 \%$ in these postabortion studies and no expulsions were reported. ${ }^{57,58}$ This finding contrasts with higher expulsion rates reported for using conventional IUDs. ${ }^{59-61}$ If a disproportion between the IUD and uterine cavity occurs, early discontinuation will be the outcome, as observed in postabortion studies (Wildemeersch, unpublished data, 2014).

\section{Immediate postpartum contraception}

IUD insertion after delivery is convenient for many women because the motivation for contraception is high and it does not interfere with breastfeeding in the early postpartum period. However, the expulsion rate with TCu380A was high (up to $25 \%-30 \%$ ) and acceptability rates low (25-30\% continuation rate at 6 months). ${ }^{62,63}$ To circumvent these high expulsion rates, a method to anchor an IUD has been attempted. The expulsion rate was reduced but still too high (approximately 10\%-12\%). ${ }^{64}$ It is hoped that a new anchoring technique for immediate postplacental insertion after vaginal delivery will eventually become available.

Immediate postplacental IUD insertion at the time of cesarean section, ie, through the hysterotomy, provides a good opportunity to achieve long-term contraception with minimal discomfort to the patient. ${ }^{65}$ No studies have shown any increase in the risk of infection or other complications related to this method of IUD insertion. Moreover, some reports indicate that women who deliver by cesarean section may have lower expulsion rates than those who deliver vaginally, with immediate IUD insertion. A recent Cochrane analysis found that the risk of expulsion associated with IUD placed at the time of cesarean section was significantly lower than the expulsion rates seen with transvaginal placement of IUDs immediately following vaginal delivery of the fetus and placenta. ${ }^{66}$

Çelen et al conducted a study in 245 Turkish women with term pregnancies delivered by cesarean section. The participants were examined before hospital discharge and at 6 weeks, 6 months, and 12 months postpartum. There was one case of an unplanned pregnancy $(0.4 \%)$. There were no serious complications associated with immediate IUD insertion during cesarean section. The cumulative rates of expulsion, removal for bleeding/pain, and other medical reasons were $17.6,8.2$, and 2.4 per 100 women per year, respectively. The continuation rates were $81.6 \%$ and $62 \%$ at 6 months and 12 months, respectively. It was concluded that immediate postplacental IUD insertion during cesarean section provides adequate protection against pregnancy. However, more than 
one fourth of the participants discontinued IUD use due to spontaneous expulsion or other medical reasons. ${ }^{67}$

Despite the fact that other studies observe a lower expulsion rate with cesarean deliveries, ${ }^{68}$ the challenge to solve the displacement and expulsion problems continues. A simple anchoring technique for the suspension of a frameless copper IUD is currently in development. This method, which is derived from the experience obtained over the years and the multitude of clinical investigations performed with the frameless copper IUD, may solve the expulsion problem and also provide either short-term or ultra-long-term contraception. Such an approach could be highly cost-effective as well, especially when the IUD cost would be incorporated in the cost of the operative procedure. Another advantage is the reversibility of the method. Long-acting copper IUDs have been compared with tubal sterilization and found to be equally effective. ${ }^{69,70}$ These devices could replace irreversible sterilization. Many women stop planning further pregnancies after their first or second cesarean section. As the anchored method is reversible, this device could be used as a sterilization or temporary method.

\section{Discussion}

It is likely that intrauterine contraception could be far more attractive if IUDs designed to fit well in the uterus were used. At least $50 \%$ of nulliparous women have an intrauterine cavity width at the fundal level of $<24 \mathrm{~mm}$, thus significantly narrower than currently available IUDs with a $28 \mathrm{~mm}$ or $32 \mathrm{~mm}$ transverse arm. It is not surprising that an IUD which is too big for the uterine cavity will often lead to early discontinuation. Health care providers should be aware that many IUD users endure pain to keep the method they have finally selected after much hesitation and for which they may have made an important financial effort.

The transverse arm of a T-shaped IUD in nulliparous women should probably be not longer than $24 \mathrm{~mm}$ and this short arm might even be too long for some women. It is known that the uterus is theoretically capable of generating forces of around $50 \mathrm{~N}$, which is sufficient to produce IUD embedment, or in some cases uterine perforation, even after the IUD is confirmed to be correctly placed using ultrasound..$^{30}$

In addition, dislocated IUDs result in higher pregnancy rates. ${ }^{71}$ Also, expulsion rates are expected to increase significantly when IUDs are misplaced or have moved away from the fundus. ${ }^{72}$ Particularly with respect to copper IUDs, when the distance between the upper end of the
IUD to the serosal surface of the uterus is $>2 \mathrm{~cm}$, as measured by ultrasound at the beginning of the menstrual cycle, removal of the IUD should be considered to protect the woman from an unintended pregnancy. Removals for downward displacement of MLCu375 and TCu380A IUDs were $12.7 \%$ and $6.0 \%$, respectively, in a Chinese study reported by $\mathrm{Wu}$ et al. ${ }^{73}$

The general principle in medicine is "First, do no harm." It is evident that if an IUD causes harmful effects, including embedment, the result will be removal of the IUD in the majority of cases. A review of recent IUD studies mentioned continuation rates as low as $48 \%$ after 1 year of use. ${ }^{74}$ The National Institute for Health and Care Excellence, UK, guidelines on LARC informed that health care professionals should be aware that up to $60 \%$ of women discontinue using LNG-IUS within 5 years because of bleeding and pain and/ or systemic progestogenic side effects. ${ }^{75}$

In the CHOICE study, the continuation rates were relatively high during the first year but they dropped rapidly thereafter, especially in adolescent women. ${ }^{76}$ Repeat teenage pregnancies are on the increase. ${ }^{77}$ In 1982, van Os, inventor of the Multiload IUD, expressed his hope to improve IUD selection by measuring the uterine cavity and inserting "tailor-made" devices. "We will then probably be able to get better continuation rates which are now between $70 \%$ and $80 \%$ for the first year of use for practically all IUCDs (intrauterine contraceptive devices). Maybe this can be enhanced to $80 \%-90 \%$." ${ }^{78}$ Many current IUDs do not belong in the uterine cavity in which they were inserted. A one-dimensional frameless IUD or IUS probably provokes the least reaction from the uterus and is likely to be universally tolerated, as clinical trials suggest. ${ }^{34,35}$

\section{Conclusion}

Young men and women are a highly vulnerable population. They deserve to be informed correctly and have access to high-quality and effective reproductive health care assistance. Discussions about contraception should address risks and benefits associated with IUDs, and the different designs that may be better tolerated and result in high use continuation. Moreover, same-day postcoital and immediate postabortion IUD insertion (or referrals to facilities that provide this service) should be offered as an option whenever possible. The consequences of unintended sex and unintended pregnancy are far too great. As adolescent pregnancy remains a huge public health problem, more research is urgently needed to study new IUD methods as those described in this article, and compare them with existing birth control methods, in adolescent and young women for interval, postcoital, and 
postabortion contraception in order to reduce the unplanned pregnancy rates in the world.

This article was written with the objective to respond to the urgent need to improve intrauterine contraception as it is probable that the objectives of LARC may not be met without significant improvement of IUD design. More widespread access to the existing IUDs may not be sufficient. Women should have access to better performing IUDs taking into account the anatomical variations in size and shape of the uterus to avoid harm and side effect which often lead to early removal of the IUD. The solution is simple but requires a revision of the current design of IUDs. One-dimensional (longitudinal) IUDs are likely to be the best option; framed devices, provided with shortened transverse arm and IUDs which adapt to the width of the uterus, are viewed as second best. One of the reasons of the higher unintended pregnancy rate in the USA compared to Western Europe may be the paucity of suitable IUDs. Appropriate IUDs could reduce this gap.

\section{Disclosure}

Dirk Wildemeersch has been involved in the optimization of new, innovative drug delivery systems for use in the uterus. He is currently an advisor in devising new concepts in controlled release for contraception, gynecological treatment, and prevention of infectious diseases. All other authors report no conflicts of interest in this work.

\section{References}

1. Trussell J. Contraceptive failure in the United States. Contraception. 2011;83:397-404.

2. Blumenthal P, Voedisch A, Gemzell-Danielson K. Strategies to prevent unintended pregnancy: increasing use of long-acting reversible contraception. Hum Reprod Update. 2011;17:121-137.

3. Secura GM, Allsworth JE, Madden T, Mullersman JL, Peipert JF. The Contraceptive $\mathrm{CHOICE}$ project: reducing barriers to long-acting reversible contraception. Am J Obstet Gynecol. 2010;203:115. e1-e7.

4. Haimovich S. Profile of long-acting reversible contraception users in Europe. Eur J Contracept Reprod Health Care. 2009;14:187-195.

5. American College of Obstetricians and Gynecologists (ACOG). Committee opinion no 539: adolescents and long-acting reversible contraception: implants and intrauterine devices. Obstet Gynecol. 2012;120:983-988.

6. Danvers AA, Stuart GS, Bryant AG. Lawsuits against Mirena ${ }^{\circledR}$ : potential impact on public health. Contraception. 2014;89:489-492.

7. Paterson H, Ashtin J, Harrison-Woolrych M. A nationwide cohort study of the use of the levonorgestrel intrauterine device in New Zealand adolescents. Contraception. 2009;79:433-438.

8. Suhonen S, Haukkamaa M, Jakobsson T, Rauramo I. Clinical performance of a levonorgestrel-releasing intrauterine system and oral contraceptives in young nulliparous women: a comparative study. Contraception. 2004;69:407-412.

9. Teal SB, Sheeder J. IUD use in adolescent mothers: retention, failure and reasons for discontinuation. Contraception. 2012;85: $270-274$.
10. Brockmeyer A, Kishen M, Webb A. Experience of IUD/IUS insertions and clinical performance in nulliparous women - a pilot study. Eur $J$ Contracept Reprod Health Care. 2008;13:248-254.

11. Garbers S, Haines-Stephan J, Lipton Y, Meserve A, Spieler L, Chiasson MA. Continuation of copper-containing intrauterine devices at 6 months. Contraception. 2013;87:101-106.

12. Berenson AB, Tan A, Hirth JM, Wilkinson GS. Complications and continuation of intrauterine device use among commercially insured teenagers. Obstet Gynecol. 2013;121:951-958.

13. Rasheed SM, Abdelmonem AM. Complications among adolescents using copper intrauterine contraceptive devices. Int J Gynaecol Obstet. 2011;115:269-272.

14. Aoun J, Dines VA, Stovall DW, Mete M, Nelson CB, Gomez-Lobo V. Effects of age, parity, and device type on complications and discontinuation of intrauterine devices. Obstet Gynecol. 2014;123:585-592.

15. Farley TM, Rosenberg MJ, Rowe PJ, Chen JH, Meirik O. Intrauterine devices and pelvic inflammatory disease: an international perspective. Lancet. 1992;339:785-788.

16. Neale R, Knight I, Keane F. Do users of the intrauterine system (Mirena) have different genital symptoms and vaginal flora than users of the intrauterine contraceptive device? Int J STD AIDS. 2009;20:423-424.

17. Everett ED, Hirschmann JV. Transient bacteremia and endocarditis prophylaxis. A review. Medicine (Baltimore). 1977;56:61-77.

18. Toivonen J, Luukkainen T, Allonen H. Protective effect of intrauterine release of levonorgestrel on pelvic infection: three years' comparative experience of levonorgestrel- and copper-releasing intrauterine devices. Obstet Gynecol. 1991;77:261-264.

19. Grimes DA. Intrauterine device and upper-genital-tract infection. Lancet. 2000;356:1013-1019.

20. Shelton JD. Risk of clinical pelvic inflammatory disease attributable to an intrauterine device. Lancet. 2001;357:443.

21. Hubacher D, Lara-Ricalde R, Taylor DJ, Guerra-Infante F, Guzman-Rodriguez R. Use of copper intrauterine devices and the risk of tubal fertility among nulligravid women. $N$ Engl J Med. 2001;345: 561-567.

22. World Health Organization. Medical Eligibility Criteria for Contraceptive Use. 4th ed; 2010. Available from: http://whqlibdoc.who. int/publications/2010/9789241563888_eng.pdf. Accessed November $15,2014$.

23. Moore KL, Persaud TVN, Torchia MG. The Urogenital System. Before We are Born: Essential of Embryology and Birth Defects. 7th ed. Philadelphia: Saunders/Elsevier; 2008:162-189.

24. Chan YY, Jayaprakasan K, Zamora J, Thornton JG, Raine-Fenning N, Coomarasamy A. The prevalence of congenital uterine anomalies in unselected and high-risk populations: a systematic review. Hum Reprod Update. 2011;17:761-771.

25. Jurkovic D, Gruboeck K, Tailor A, Nicolaides KH. Ultrasound screening for congenital uterine anomalies. Br J Obstet Gynaecol. 1997; 104:1320-1321.

26. Grimbizis GF, Gordts S, Di Spiezio A, et al. The ESHRE/ESGE consensus on the classification of female genital tract congenital anomalies. Hum Reprod. 2013;28:2032-2044.

27. Shipp TD, Bromley B, Benacerraf BR. The width of the uterine cavity is narrower in patients with an embedded intrauterine device (IUD) compared to a normally positioned IUD. J Ultrasound Med. 2010;29:1453-1456.

28. Hasson HM. Clinical studies of the wing sound II metrology device. In: Zatuchni GI, Goldsmith A, Sciarra JJ, editors. Intrauterine Contraception: Advances and Future Prospects. Philadelphia: Harper and Row; 1984:126-141

29. Kurz KH. Cavimeter uterine measurements and IUD clinical correlation. In: Zatuchni GI, Goldsmith A, Sciarra JJ, editors. Intrauterine Contraception: Advances and Future Prospects. Philadelphia: Harper and Row; 1984:142-162.

30. Goldstuck N, Wildemeersch D. Role of uterine forces in intrauterine device embedment, perforation, and expulsion. Int $J$ Womens Health. 2014;6:735-744. 
31. Kaislasuo J, Heikinheimo O, Lähteenmäki P. Predicting painful or difficult intrauterine device insertion in nulliparous women. Obstet Gynecol. 2014;124:345-353.

32. Benacerraf BR, Shipp TD, Lyons JG, Bromley B. Width of the normal uterine cavity in premenopausal women and effect of parity. Obstet Gynecol. 2010;116:305-310.

33. Nelson A, Apter D, Hauck B, et al. Two low-dose levonorgestrel intrauterine contraceptive systems: a randomized controlled trial. Obstet Gynecol. 2013;122:1205-1213.

34. Wildemeersch D, Pett A, Jandi S, Hasskamp T, Rowe P, Vrijens M. Precision intrauterine contraception may significantly increase continuation of use: a review of long-term clinical experience with frameless copper-releasing intrauterine contraception devices. Int $J$ Womens Health. 2013;5:215-225.

35. Wildemeersch D, Jandi S, Pett A, Nolte K, Hasskamp T, Vrijens M. Use of frameless intrauterine devices and systems in young nulliparous and adolescent women: results of a multicenter study. Int $J$ Womens Health. 2014;6:727-734.

36. Eisenberg D, McNicholas C, Peipert JF. Cost as a barrier to long-acting reversible contraceptive (LARC) use in adolescents. J Adolesc Health. 2013;52:S59-S63.

37. Peipert JF, Madden T, Allsworth JE, Secura GM. Preventing unintended pregnancies by providing no-cost contraception. Obstet Gynecol. 2012;120:1291-1297.

38. WHO Scientific Group on the Mechanism of Action Safety and Efficacy of Intrauterine Devices World Health Organization. Mechanism of action, safety and efficacy of intrauterine devices. Report of a WHO scientific group. World Health Organization technical report series 753 . 1987; Geneva; 1-91.

39. Center for Disease Control and Prevention (CDC). Division of reproductive health, National center for chronic disease prevention and health promotion. US medical eligibility criteria for contraceptive use. Recommendations and Reports. June 18, 2010/59(RR04); Atlanta, GA; $1-6$.

40. Wildemeersch D, Parewijck W, Van Kets H, Delbarge W, Vrijens M, Thiery M. Misconceptions about intrauterine devices. In: Coll Capdevilla C, Iglesias Cortit L, Creatsas G, editors. Contraception Today: Proceedings of the 4th Congress of the European Society of Contraception. New York: Parthenon Publishing; 1997:145-153.

41. Ortiz NE, Croxatto HB. Copper-T intrauterine device and levonorgestrel intrauterine system: biological bases of their mechanism of action. Contraception. 2007;75:S16-S30.

42. Michie L, Cameron ST, Glasier A, Wellings K, Loudon J. Myths and misconceptions about intrauterine contraception among women seeking termination of pregnancy. J Fam Plann Reprod Health Care. 2014;40: $36-40$.

43. Asker C, Stokes-Lampard H, Beavan J, Wilson S. What is it about intrauterine devices that women find unacceptable? Factors that make women non-users: a qualitative study. J Fam Plann Reprod Health Care. 2006;32:89-94.

44. Angioli R, De Cicco Nardone C, Plotti F, et al. The use of music to reduce anxiety during office hysteroscopy: a prospective randomized trial. J Minim Invasive Gynecol. 2014;21:454-459.

45. Ward K, Jacobson JC, Turok DK, Murphy PA. A survey of provider experience with misoprostol to facilitate intrauterine device insertion in nulliparous women. Contraception. 2011;84:594-599.

46. Scavuzzi A, Souza AS, Costa AA, Amorim MM. Misoprostol prior to inserting an intrauterine device in nulligravidas: a randomized clinical trial. Hum Reprod. 2013;28:2118-2125.

47. Arvidsson C, Helborg M, Gemzell-Danielsson K. Preference and acceptability of oral versus vaginal administration of misoprostol in medical administration of misoprostol in medical abortion with mifepristone. Eur J Obstet Gynecol Reprod Biol. 2005;123:87-91.

48. Dermish AI, Turok DK, Jacobson JC, Flores MES, McFadden M, Burke K. Failed IUD insertions in community practice: an under-recognized problem? Contraception. 2013;87:182-186.
49. Akin MD, Weingand KW, Hengehold DA, Goodale MB, Hinkle RT, Smith RP. Continuous low-level topical heat in the treatment of dysmenorrhea. Obstet Gynecol. 2001;97:343-349.

50. Lippes J, Malik T, Tatum HJ. The postcoital copper-T. Adv Plan Parent. 1976;11:24-29.

51. Cleland K, Zhu H, Goldstuck N, Cheng L, Trussel J. The efficacy of intrauterine devices for emergency contraception: a systematic review of 35 years of experience. Hum Reprod. 2012;27:1994-2000.

52. Trussell J, Schwarz EB. Emergency contraception. In: Hatcher RA, Trussell J, Nelson AL, Cates W, Cawal D, editors. Contraceptive Technology. 20th ed. New York: Ardent Media Inc; 2008:779-863.

53. Mishell D. Intrauterine devices: mechanisms of action, safety, and efficacy. Contraception. 1998;58:45S-53S.

54. Schwarz EB, Kavanaugh M, Douglas E, Dubowitz T, Creinin MD. Interest in intrauterine contraception among seekers of emergency contraception and pregnancy testing. Obstet Gynecol. 2009;113: 833-839.

55. Reeves MF, Smith KJ, Creinin MD. Contraceptive effectiveness of immediate compared to delayed insertion of intrauterine devices after abortion: a decision analysis. Obstet Gynecol. 2007;109: $1286-1294$

56. Gemzell-Danielsson K, Kopp Kallner H, Faúndes A. Contraception following abortion and the treatment of incomplete abortion. Int $J$ Gynaecol Obstet. 2014;126:S52-S55.

57. Batár I, Wildemeersch D, Vrijens M, Delbarge W, Temmerman M, Gbolade BA. Preventing abortion and repeat abortion with the GyneFix ${ }^{\mathbb{R}}$ intrauterine implant system - preliminary results. Adv Contracept. 1998;14:91-96.

58. Gbolade BA. Immediate insertion of the postabortion version of GyneFix $^{\circledR}$ intrauterine implant system. Contemp Rev Obstet Gynaecol. 1999;11:29-33.

59. Goodman S, Hendlish SK, Benedict C, Reeves MF, Pera-Floyd M, Foster-Rosales A. Increasing intrauterine contraception use by reducing barriers to post-abortal and interval insertion. Contraception. 2008;78:136-142.

60. Goodman S, Hendlish SK, Reeves MF, Foster-Rosales A. Impact of immediate postabortal insertion of intrauterine contraception on repeat abortion. Contraception. 2008;78:143-148.

61. Bednarek PH, Creinin MD, Reeves MF, Cwiak C, Espey E, Jensen JT. Post-aspiration IUD randomization (PAIR) study trial group. Immediate versus delayed IUD insertion after uterine aspiration. $N$ Engl $J$ Med. 2011;364:2208-2217.

62. Grimes D, Schulz K, Van Vliet H, Stanwood N. Immediate postpartum insertion of intrauterine devices. Cochrane Database Syst Rev. 2003;12(1):CD003036.

63. Chen BA, Reeves MF, Hayes JL, Hohmann HL, Perriera LK, Creinin MD. Postplacental or delayed insertion of the levonorgestrel intrauterine device after vaginal delivery: a randomized controlled trial. Obstet Gynecol. 2010;116:1079-1087.

64. Tatum HJ, Beltran RS, Ramos R, Van Kets H, Sivin I, Schmidt FH. Immediate postplacental insertion of GYNE-T 380 and GYNE-T 380 postpartum intrauterine contraceptive devices: randomized study. Am J Obstet Gynecol. 1996;175:1231-1235.

65. Goldstuck ND, Steyn PS. Intrauterine contraception after cesarean section and during lactation: a systematic review. Int $J$ Womens Health. 2013;5:811-818

66. Kapp N, Curtis KM. Intrauterine device insertion during the postpartum period: a systematic review. Contraception. 2009;80:327-336.

67. Çelen S, Möröy P, Sucak A, Aktulay A, Danişman N. Clinical outcomes of early postplacental insertion of intrauterine contraceptive devices. Contraception. 2004;69:279-282.

68. Zhou SW, Chi IC. Immediate postpartum IUD insertions in a Chinese hospital - a two year follow-up. Int J GynaecolObstet. 1991;35: 157-164.

69. Grimes D, Mishell D Jr. Intrauterine contraception as an alternative to interval tubal sterilization. Contraception. 2008;77:6-9. 
70. Wu JP, Pickle S. Extended use of the intrauterine device: a literature review and recommendations for clinical practice. Contraception. 2014;89:495-503.

71. Anteby E, Revel A, Ben-Chetrit A, Rosen B, Tadmor O, Yagel S. Intrauterine device failure: relation to its location within the uterine cavity. Obstet Gynecol. 1993;81:112-114.

72. Pimentel E, Diaz J, Bahamondes L. The use of vaginal ultrasound to indentify copper T IUDs at high risk of expulsion. Contraception. 1996;54:287-289.

73. Wu SC, Li L, Zou Y, Dong J, Lei ZW. Clinical effect comparison of seven types of IUD placement during intermenstruum. Chin J Fam Plann. 2008; 16:552-556.

74. Deans EI, Grimes DA. Intrauterine devices for adolescents: a systematic review. Contraception. 2009;79:418-423.

75. National Institute for Health and Clinical Excellence. Long-Acting Reversible Contraception. NICE Clinical Guidelines 30. London: RCOG; 2005.
76. O’Neil-Calahan M, Peipert JF, Zhao Q, Madden T, Secura G. Twenty-four-month continuation of reversible contraception. Obstet Gynecol. 2013;122:1083-1091.

77. Collier J. The rising proportion of repeat teenage pregnancies in young women presenting for termination of pregnancy from 1991 to 2007. Contraception. 2009;79:393-396.

78. Tadesse E, Wamsteker K. Evaluation of 24 patients with IUD-related problems. Eur J Obstet Gynecol Reprod Biol. 1985;19:37-41.

79. medipay.de [homepage on the Internet]. Medipay. Available from: https://www.medipay.de/. Accessed December 3, 2014.

80. Xiong X, Buekens P, Wollast E. IUD use and risk of ectopic pregnancy: a meta-analysis of case-control studies. Contraception. 1995;52(1):23-34.

81. Bahamondes L, Mansour D, Fiala C, Kaunitz AM, GemzellDanielsson K. Practical advice for avoidance of pain associated with insertion of intrauterine contraceptives. J Fam Plann Reprod Health Care. 2014;40:54-60.
Open Access Journal of Contraception

\section{Publish your work in this journal}

Open Access Journal of Contraception is an international, peerreviewed, open access, online journal, publishing original research, reports, reviews and commentaries on all areas of contraception. In addition to clinical research, demographics and health-related aspects, the journal welcomes new findings in animal and preclinical studies

\section{Dovepress}

relating to understanding the biological mechanisms and practical development of new contraceptive agents. The manuscript management system is completely online and includes a very quick and fair peer-review system. Visit http://www.dovepress.com/testimonials.php to read real quotes from published authors. 